\title{
O SETOR INDUSTRIAL E SEUS EFEITOS NO MERCADO DE TRABALHO FORMAL: UMA ANÁLISE PARA O TRIÂNGULO CRAJUBAR-CE (2008-2018)
}

\section{Carlos Eduardo Pereira do Nascimento ${ }^{1}$}

\section{INTRODUÇÃO}

As repercussões do processo de industrialização no Brasil nas diversas escalas espaciais (nacional, regional e local), iniciado em 1933 e com forte dinamismo a partir dos anos 1950, colocaram o país em um patamar significativo no mercado internacional. $O$ aparato estatal (iniciado pelo Governo de Getúlio Vargas (GV)) foi de suma importância na promoção industrial, com a criação de diversas instituições (CSN, Companhia Vale do Rio Doce, CHESF, BNB, Petrobrás, SUDENE, SERPRO, CODEVASF etc.) (CANO, 2007, 2012; CAPUTO; MELO, 2009; FURTADO, 2005; MINISTÉRIO DA ECONOMIA, 2015).

Com a crise do Welfare State, abertura comercial, desregulamentações no mercado, enxugamento da folha salarial das empresas, bem como maiores exigências quanto à qualificação e polivalência da mão de obra, levaram a um mercado altamente competitivo nos anos 1980-90, com a diminuição da participação da indústria na economia brasileira. Com a evidência latente das disparidades regionais, o Nordeste entra no bojo das ações do governo rumo à industrialização através da SUDENE e coordenação de Celso Furtado (ANTUNES, 2009; ARAUJO, 2000; LIMA JUNIOR, 2014).

O Nordeste, diferentemente da realidade macro, apresentou bom desempenho no emprego industrial pela relocalização espacial da indústria e aos efeitos dos incentivos fiscais dados pelos Estados para atrair as indústrias. Nesse contexto, três estados se destacam: Bahia, Ceará e Pernambuco. O segundo estado em questão auferiu um complexo industrial a partir da "Era das Mudanças" na década de 1980, envolto pelo ideário neoliberal e modernista iniciado na época (ARAÚJO, 2007; ARRUDA et al., 1999; LIMA JUNIOR, 2014a, 2014b).

A RM Cariri, localizada no sul do estado, ganha destaque pelas políticas de desconcentração demográfica e econômica promovidas pelo governo estadual. Destarte, o

\footnotetext{
${ }^{1}$ Mestrando em Economia pelo Programa de Pós-Graduação em Economia da Universidade Federal do Rio Grande do Norte (PPECO/UFRN). Graduado em Economia pela Universidade Regional do Cariri (URCA). Pesquisador do Grupo de Estudos em Territorialidades Econômicas e Desenvolvimento Regional e Urbano (GETEDRU), vinculado ao Departamento de Economia da URCA, e do Grupo de Estudos e Pesquisas em Espaço, Trabalho, Inovação e Sustentabilidade (GEPETIS), vinculado ao Departamento de Economia e do PPECO da UFRN. Tem experiência na área de economia, com ênfase em economia regional e urbana e economia do trabalho. E-mail: eduardocarlos2807@gmail.com.
} 
CRAJUBAR, centro econômico da região, tornou-se um dos polos de desenvolvimento interregional do Nordeste com influência considerável que ultrapassa os limites territoriais, atingindo outros estados como o Piauí, Pernambuco e a Paraíba (BESERRA, 2006, 2007; OLIVEIRA; APOLINÁRIO; PEREIRA, 2013; OLIVEIRA, 2014).

Diante disso, o presente trabalho tem como objetivo analisar o mercado de trabalho formal sob a ótica do setor industrial no CRAJUBAR para os anos 2008 e 2018, evidenciando o panorama da economia da região via indústria, bem como as repercussões sobre a institucionalização da Região Metropolitana do Cariri (RM Cariri), em 20092.

Além desta introdução e das considerações finais, o artigo está dividido em três seções: a segunda seção trata, de forma concisa, dos processos de industrialização brasileira, nordestina e cearense buscando entender a inserção da RM Cariri, logo, do CRAJUBAR no padrão industrial. A seção seguinte trata da metodologia do trabalho. Por fim, a penúltima seção analisa o setor industrial do CRAJUBAR nos anos 2008 e 2018.

\section{AS INDUSTRIALIZAÇÕES: BRASIL, NORDESTE E CEARÁ 2.1 A INDUSTRIALIZAÇÃO PARA O BRASIL}

O processo de industrialização inicia sua trajetória no Brasil a partir da década de 1930, mais especificamente 1933 (CANO, 2012), decorrente da transição do modelo primário exportador para um novo padrão de acumulação através do deslocamento do centro dinâmico, corolário da crise de 1929, (crescimento para dentro) (FURTADO, 2005), rumo a um novo complexo, o da industrialização. Esse contexto está conectado a tentativa de 'quebrar a espinha' - parafraseando Wilson Cano, do sistema cafeeiro. Todavia, não existia mais monocultura ou um único sistema, mas sim uma economia capitalista munida de um grau avançado de inter-relações setoriais, ou seja, quebrar essa espinha significaria quebrar o incipiente capitalismo brasileiro. Para tanto, 0 papel do Estado foi de grande valia.

O aparato político de GV durante seu mandato conforma um conjunto de medidas que reforçam o papel do Estado no processo de industrialização brasileiro (CANO, 2012). Há quem mencione que o processo de industrialização brasileira ocorrera antes dos anos 1930, como Versiani e Versiani (1975) e Fishlow (1972), os quais destacam eventos que mesmo involuntariamente desencadeariam ambiente favorável à industrialização, por exemplo, as guerras, a depressão, o célere crescimento demográfico, as políticas de valorização do café etc., ou até mesmo que o Processo de Substituição de Importações (PSI) aparecera em menor

\footnotetext{
${ }^{2}$ Criado pela Lei Complementar no 78 , em 26 de junho de 2009.
} 
expressão no inicio do período republicano iniciado em 1889. Contudo, Cano (2012) refuta esta ideia ao atestar que a indústria existente antes da década de 1930 não se configura de fato um processo de industrialização, pois estava subordinada ao setor de exportações, "seja pelo uso de divisas por ele geradas, seja pelo mercado de consumo que criou ou pela dependência do uso do excedente que criava" (CANO, 2012, p. 912).

A partir de 1933 a economia brasileira se recupera, sob a égide da indústria, absorvendo a capacidade ociosa via PSI. O principal setor industrial era o de bens de consumo não durável. A indústria, segundo Cano (2007), já apresentava resultados expressivos: entre 1919 e 1939 mais que triplica seu produto real e entre 1939 e 1949 mais que duplica durante a industrialização 'restringida'.

Nos anos 1940 sob o poder de Getúlio Vargas a ação do Estado fortalece reificada pela criação de diversas estatais de grande importância como a Companhia Siderúrgica Nacional (CSN) em 1941, a Companhia Vale do Rio Doce em 1942, a Companhia Hidroelétrica do São Francisco (CHESF) em 1945 e a Comissão do Vale do São Francisco (CVSF) em 1948. Já na década de 1950, ainda sob seu Governo foram criados o Banco Nacional de Desenvolvimento Econômico (BNDE) e Banco do Nordeste do Brasil (BNB) em 1952 e a Petrobrás (1953) (CANO, 2007; CAPUTO; MELO, 2009; MINISTÉRIO DA ECONOMIA, 2015).

Na época da industrialização pesada (1956-70) (CANO, 2007), o Plano de Metas de Juscelino Kubitschek (JK) (1956-61) acelerou os passos brasileiros rumo a um aparato industrial complexo, acelerando, os setores de bens de produção e consumo durável, via investimentos nacionais, estatais e estrangeiros (CANO, 2007; CAPUTO; MELO, 2009). Ademais, diante das desigualdades regionais latentes, o governo se movimenta em prol do desenvolvimento econômico da região Nordeste sob a coordenação de Celso Furtado através da Superintendência para o Desenvolvimento do Nordeste (SUDENE) em 1959 (LIMA JUNIOR, 2014a).

A partir de 1964, o comando dar-se pelo exército brasileiro. Algumas ações são tomadas, como o paulatino esvaziamento da SUDENE que acentua novamente as desigualdades regionais e atrasa seu desenvolvimento via industrialização, diversas reformas (tributária, bancária etc.) e a criação de algumas estatais, tais como o Serviço Federal de Processamento de Dados (SERPRO) em 1964, a Embraer e os Correios em 1969, Telebrás e Embrapa em 1972, a Infraero em 1973, a Companhia de Desenvolvimento dos Vales do São Francisco e do Parnaíba (CODEVASF) e Dataprev em 1974 etc. (MINISTÉRIO DA ECONOMIA, 2015), além do Plano de Ação Econômica do Governo (PAEG), entre 1964-66, o qual objetivava estabilidade de preços vis-à-vis uma inflação galopante, aumento dos investimentos diretos, reformas no sistema (KERECKI; SANTOS, 2009) e dos Planos Nacionais de Desenvolvimento I e II (1972-74 e 1974-79, respectivamente) na 
tentativa de melhorar a estrutura industrial brasileira através da produção de bens mais sofisticados, como os bens de capital, mesmo diante das instabilidades internacionais como os dois choques do petróleo (1973 e 1979) (BATISTA, 1987; SALLES FILHO, 2002).

A década de 1980 foi frustrante não só para o Brasil, mas para grande parte do mundo. Conhecida como a 'década perdida', este período caracteriza-se por uma forte crise externa dos países industrializantes não detentores de petróleo. Com a desvalorização do dólar estadunidense nos anos 1970, na década seguinte o Federal Reserve (Fed) lança um pacote monetário contracionista para conter a depreciação. Tanto que nesta situação nenhum outro país sofreu tanto os efeitos severos como o Brasil em decorrência da antiga dependência de importação de petróleo somada agora a vultosos pagamentos de juros e amortizações aos credores externos (SALOMÃO, 2016).

Já a década de 1990 marca a inserção do Brasil na lógica neoliberal implementada duas décadas antes, com abertura comercial e financeira ampliando a concorrência. Todavia, esta situação sucateou a indústria nesse período, de forma que o setor de Serviços assume-se o posto principal na geração de empregos. Este período, ademais, marca os novos padrões de trabalho e as novas relações no mercado de trabalho, via desregulamentações, polivalência e qualificação como critérios para o trabalhador, empresas com mais capital investido e menor corpo de funcionários etc., a qual abriu portas para uma ampliação descomunal de novas (e velhas) modalidades de (super) exploração do trabalho, desigualmente impostas e globalmente combinadas pela nova divisão internacional do trabalho (ANTUNES, 2009). A despeito dessa situação adversa do setor industrial nos anos 1990, no século XXI a indústria se reposiciona no mercado seguindo as novas 'leis' concorrenciais do capitalismo.

Atinente à questão regional, a indústria tem papel importante na desconcentração regional através do espraiamento para outros centros e para o interior como mecanismo de desenvolvimento de áreas pouco desenvolvidas economicamente.

\subsection{A INDUSTRIALIZAÇÃO PARA O NORDESTE}

A ideia de industrialização para o Nordeste dar-se a partir da institucionalização da SUDENE tratando com mais calma do planejamento regional e atenuação das disparidades entre as regiões, ou seja, uma intervenção governamental no Nordeste via SUDENE (LIMA JUNIOR, 2014a). Esta ideia se intensifica no começo da década de 1960 com um esforço intensivo em 
industrializar o Nordeste, baseado no sistema 34/18-Finor ${ }^{3}$. A política implementada para a industrialização nordestina focou em certos objetivos como acelerar o crescimento econômico da região, fortalecer e diversificar sua base econômica, reduzir sua dependência a bens importados e aumentar o poder de absorção de mão de obra nos principais centros da zona urbana.

A despeito da iniciativa da SUDENE por Celso Furtado, principalmente, a política de industrialização aplicada por JK para o Brasil era ótima, porém para o Nordeste era ruim em alguns aspectos como a ampliação das desigualdades regionais. Os objetivos de JK circulavam pela busca incessante de transformar o Brasil em país industrial. 0 grande problema era (e ainda é) que a indústria se concentrava no Sudeste e a política federal não incorporava a visão regional tão necessária (ARAUJO, 2000). Além disso, tinha a visão sempre errônea de relacionar o nível econômico do Nordeste exacerbadamente com o fenômeno da seca. "O problema do Nordeste não é a seca, é a reconfiguração do desenvolvimento brasileiro e como a região está se inserindo nela [...] e [...] a seca não era a causa do problema do Nordeste, [...] é consequência dos problemas do Nordeste" (ARAUJO, 2000, p. 76). Além disso, há a herança colonialista, a lenta recuperação de suas exportações, a difícil complementaridade da economia sulista e os interesses das elites regionais sobrepujando o bem estar comum da região, levando a intervenção do Governo na aplicação de políticas regionais em prol do desenvolvimento da região (CANO, 1977; ALVES; PEREIRA; LIMA JUNIOR, 2019).

A atração de indústrias para a região via sistema 34/18-Finor é favorável, por um lado, pois contribui para acelerar o crescimento econômico e modernizar e diversificar o parque industrial da região. Por outro lado, com sedes fora do Nordeste, a presença dessas indústrias traz a ideia de uma efetiva desregionalização do controle da indústria regional, ou seja, constitui-se como elemento-chave no processo de homogeneização do espaço econômico nacional (REDWOOD, 1984).

Em 1960, as indústrias tradicionais até então detinham quase 60\% do valor agregado da indústria nordestina (setores têxtil, mineração e de alimentos). Em 1977, a realidade é outra: os mesmos setores correspondem somente a $37 \%$, tendo aumentado a participação de setores mais sofisticados como a metalurgia, mecânica, elétrica, comunicações, química etc. (REDWOOD, 1984).

Entre os anos 1970 e 1990, apontaram avanços, inclusive a indústria no Nordeste apresentou crescimento significativo nos anos 1950-85 com números superiores a 10\% (exceção

\footnotetext{
${ }^{3}$ Sua característica básica era a de estimular os investimentos nos diversos setores da economia do Nordeste mediante fornecimento de subsídios a formação de capital, sobretudo pelo setor privado (REDWOOD, 1984; LIMA JUNIOR, 2014a).
} 
de 1980-85), no momento de industrialização intensiva que o país convivia antes da década perdida (LIMA JUNIOR, 2014a). A década de 1990, marcada pela conjuntura neoliberal que se apresenta ao Brasil, com o esvaziamento da instituição coordenadora do planejamento regional (SUDENE), viu-se os grandes estados nordestinos Bahia, Ceará e Pernambuco iniciarem uma estratégia de concessão de incentivos, a conhecida guerra fiscal, a qual deteriora as condições financeiras dos estados e municípios (CARVALHO, 2018).

A despeito do efeito nocivo dessa medida, entre 2002 e 2015, a economia da região Nordeste apresentou expansão superior à observada na economia brasileira (CARVALHO, 2018), movimentada pelas ações dos governos pró-Nordeste no que diz respeito à questão regional.

\subsection{A INDUSTRALIZAÇÃO PARA O CEARÁ: UM OLHAR PARA O CRAJUBAR}

O processo de industrialização cearense dar-se em três períodos: 1) final do século XIX até os anos 1950, o qual marca o período de instalação das primeiras indústrias têxteis, do beneficiamento de sementes e do curtimento de couros; 2) dos anos 1960 até meados dos anos 1980, onde ocorre de forma incipiente à industrialização do estado, com a crise do setor agrícola e investimentos na modernização de indústrias já existentes e implantação de novos segmentos industriais; e 3) de meados dos anos 1980 até os dias atuais; período este mais significativo pela perspectiva modernizadora que o Governo estadual aplica no Ceará através das ações dos Governos Tasso Jereissati e Ciro Gomes (1987 a 2002) (AMORA, 2007; BESERRA, 2007; LIMA JUNIOR, 2014b).

O período de maior importância para o dinamismo industrial cearense é na década de 1980 - pelas ações promovidas pelo Governo a partir de 1986 até 2002, período conhecido como Era das Mudanças -, pois é neste período que no Ceará ocorrem "ações modernizadoras, dá-se a implantação do ideário neoliberal e a Região Metropolitana de Fortaleza torna-se mais dinâmica, econômica e espacialmente, atingindo envergadura nacional" (ARAÚJO, 2007, p. 99). Todavia, cabe frisar as importantes contribuições dos 'coronéis' para o quadro econômico e a organização do espaço cearense, pois oferecem o alicerce necessário para a consolidação do terceiro período de industrialização do estado, sobretudo seu último representante, Virgílio Távora (1963-66 e 1979-82), com importantes obras infraestruturais e uma das marcas de desenvolvimento da época, os incentivos fiscais (ARAÚJO, 2007; LIMA JUNIOR, 2014b). Diferentemente dos demais estados do Nordeste, foram os empresários do Ceará que patrocinaram seu processo de industrialização. "Fortaleceram-se internamente e, fortes, conseguiram derrubar a oligarquia e se tornaram hegemônicos no estado. Conseguiram fazer o que Celso Furtado sonhou" (ARAUJO, 2000, p. 79). 
A época objetivava-se integrar ao estado o III polo industrial do Nordeste, tanto que fora criado o Fundo de Desenvolvimento Industrial do Ceará (FDI) que, segundo Carleial (1983), conseguiu ser mais eficiente que as ações tomadas pela SUDENE, Banco do Brasil, BNDES e BNB. Apesar destas ações, não houve êxito, tanto que as vocações produtivas do estado ficaram em três setores: têxtil, alimentar e calçadista. Nesse contexto, as condições de modernização somente serão propiciadas a partir do processo de redemocratização do Brasil, com a eleição de Tasso Jereissati em 1986, representante dos empresários. A ideia era inserir o Ceará no modelo de mundialização da produção, ou seja, inserir o estado na lógica neoliberal de mercado visando elevar a produtividade e rentabilidade do capital. Dessa forma, o Ceará passa a ter elementos característicos da reestruturação produtiva e políticas de cunho neoliberal (ARAÚJO, 2007; LIMA JUNIOR, 2014b).

O Ceará, até então com parca capacidade de investimento relacionada à baixa poupança privada, apresentando baixa instrução e/ou qualificação na mão de obra, encontrava-se num círculo vicioso de subdesenvolvimento característico de regiões complementares ao processo de acumulação capitalista. Contudo, diferente das expectativas colocadas para o estado, viu-se um Ceará com "uma surpreendente capacidade de gerar indicadores macroeconômicos positivos, notadamente entre os indicadores relativos de crescimento, embora os indicadores sociais pouco tenham se alterado" (ARRUDA et al., 1999, p. 438), destacando-se no cenário regional pelo significativo contingente de indústrias atraído via subsídios, melhorias infraestruturais, modernização produtiva e renovação administrativa (LIMA JUNIOR, 2019). Convém ainda salientar o importante papel das mulheres no mercado de trabalho cearense, pois estas conseguem suprir marginalmente a carência de mão de obra especializada no estado (ALVES; PEREIRA; LIMA JUNIOR, 2019; ARRUDA et al., 1999).

É na década de 1990 que a dinâmica de promoção da atividade industrial se intensifica ancorada pela concessão de estímulos fiscais, os quais foram importantes na promoção da interiorização econômica, fazendo a rede urbana estadual sofrer importantes transformações. 0 número de empresas instaladas no Ceará aumenta consideravelmente (LIMA JUNIOR, 2014b; PEREIRA JUNIOR, 2012). A evolução do mercado de trabalho formal cearense é significativa (1985-2008) "uma vez que, nas últimas décadas, o Ceará apresentou um desempenho superior ao da região Nordeste e do Brasil" (PEREIRA JUNIOR, 2012 p. 123). Entrementes, o processo de industrialização no Ceará dar-se espacialmente seletivo, onde algumas regiões do Estado se beneficiam tais como a Região Metropolitana de Fortaleza (RMF) e alguns municípios do interior como Crato, Juazeiro do Norte e Sobral. 
Em suma, o estado do Ceará passa por profundas transformações que o colocam como espaço de expansão do capital, assumindo papeis econômicos e territoriais não só na região Nordeste, mas no país (PEREIRA JUNIOR, 2012). Assim, deve-se considera-lo "fração do espaço total do planeta, cada vez mais aberto as influências exógenas e aos novos signos contemporâneos [...] com objetivos claros de inserir-se no circuito da produção e consumos globalizados" (ELIAS; SAMPAIO, 2002, p. 11).

Doravante, dando atenções ao objeto deste trabalho, o triângulo CRAJUBAR apresenta importância significativa dentro e fora do território estadual, explicada pela centralidade comercial e de serviços exercida por Crato e Juazeiro do Norte que polariza muitos municípios de estado limítrofes como a Paraíba, o Pernambuco e o Piauí.

A RM Cariri, a qual o CRAJUBAR faz parte, está localizada na mesorregião sul cearense, formada por nove municípios, a saber: Barbalha, Caririaçu, Crato, Farias Brito, Jardim, Juazeiro do Norte, Missão Velha, Nova Olinda e Santana do Cariri, a qual compõe espaço geográfico atípico em relação às características do Semiárido nordestino. Sua criação advém de processos diversos que podem ser atribuídos ao comportamento das diversas escalas promovidos pelas transformações estruturais do sistema capitalista, pela importância que as cidades médias auferem nas últimas décadas expressa pelos municípios do CRAJUBAR, além dos instrumentos governamentais de interiorização do crescimento econômico no Ceará, na tentativa de atenuar as disparidades demográficas e econômicas presentes no estado (CORDEIRO, 2015; LIMA JÚNIOR, 2013).

A industrialização desta região dar-se através das transformações imanentes à fase mais recente da industrialização cearense, compreendida no final da segunda fase de industrialização cearense (1960-80), tendo maior intensidade a partir de 1995 com a volta de Tasso Jereissati ao Governo do Estado, promovendo seu "Programa de Promoção Industrial e Atração de Investimentos", o qual objetivava promover a divulgação de oportunidades de investimentos industriais via estímulos ficais e financeiros, apoio tecnológico, mercado e infraestrutura, atraindo capital de outras regiões e países. O Programa assentava-se em cinco ações prioritárias (programas de interiorização; programa de promoção industrial; programa mineral; programa de desenvolvimento tecnológico industrial e projetos especiais) envolvendo um objetivo central: interiorização do desenvolvimento (BESERRA, 2006, 2007, 2009; OLIVEIRA; APOLINÁRIO; PEREIRA, 2013; OLIVEIRA, 2014).

A promoção do desenvolvimento industrial é dada via incentivo do Imposto sobre Circulação de Mercadorias e Serviços (ICMS) às empresas de caráter econômico importante para 0 desenvolvimento do estado. As renuncias de ICMS poderiam chegar até a $75 \%$, sendo 
financiadas por mecanismos de caráter regional através do Fundo de Investimentos do Nordeste (FINOR) e o Fundo Constitucional de Financiamento do Nordeste (FNE). O resultado disso foi uma desconcentração concentrada pelo fato de se criar outras regiões que concentram parcela do produto do Estado (além da RMF) (BESERRA, 2007; OLIVEIRA, 2014).

O resultado dessa política no CRAJUBAR foi o aumento significativo de estabelecimentos, consolidando um mercado de trabalho considerável para a região. Com o desenvolvimento da industrialização, o CRAJUBAR aportou outros equipamentos e instituições como o SEBRAE, a FIEC e suas casas (SESC, SENAI, SESI), a SINDINDÚSTRIA, o SINE-IDT. Ademais, cabe destacar a educação da região pela presença de Instituições de Ensino Superior (IES) como a Universidade Regional do Cariri (URCA), presente desde os anos 1980 e da Universidade Federal do Ceará (UFC), agora do Cariri (UFCA) (BESERRA, 2009; LIMA JUNIOR; MACEDO, 2014; OLIVEIRA; 2014).

Destarte, o triangulo CRAJUBAR tornou-se um dos polos de desenvolvimento do estado do Ceará, transformando a região em um centro sub-regional com influência em considerável parte do Nordeste, ultrapassando limites territoriais, passando pelos sertões piauienses, por Pernambuco e pelo extremo oeste da Paraíba (OLIVEIRA; APOLINÁRIO; PEREIRA, 2013).

\section{METODOLOGIA}

A metodologia utilizada é de caráter exploratório. O meio técnico utilizado foi o estatístico, pois, segundo Prodanov e Freitas (2013, p. 36), o papel deste método "é, essencialmente, possibilitar uma descrição quantitativa da sociedade, considerada como um todo organizado". 0 presente trabalho tem como área de pesquisa o triangulo CRAJUBAR, formado por três municípios, a saber: Crato, Juazeiro do Norte e Barbalha, tendo como foco de análise o setor industrial formal. Faz-se uso de microdados, referentes aos anos de 2008 e 2018, provenientes do banco de dados da Relação Anual de Informações Sociais (RAIS) do Ministério do Trabalho e Emprego (MTE) e do Instituto Brasileiro de Geografia e Estatística (IBGE). Em seguida, fez-se a retirada e organização dos dados em tabelas, classificando-os a partir de algumas variáveis de análise (sexo, grau de instrução, faixa salarial e faixa etária). Posteriormente tem-se a análise dos dados.

\section{RESULTADOS E DISCUSSÕES: A INDÚSTRIA NO MERCADO DE TRABALHO FORMAL DO CRAJUBAR}


A RM Cariri, em especial o CRAJUBAR, constitui-se em uma região com expressiva importância regional, incluindo a tradicional comercialização de produtos rurais provenientes do desenvolvimento da agricultura no sopé dos vales irrigados da região do Cariri, da riqueza paleontológica, geológica e biológica presente no Geoparque Mundial Araripe (primeiro parque geológico das Américas reconhecido pela UNESCO em 2006), do turismo de aventura e do turismo religioso na figura do Padre Cicero Romão Batista e dos eventos reconhecidos regional e nacionalmente (Expocrato, Festa de Santo Antônio etc.) (ARAUJO, 2005; ARAUJO, 2018; UNESCO, 2020).

Aárea de estudo, CRAJUBAR, é composta por três municípios, Barbalha, Crato e Juazeiro do Norte. Juntos possuem quase meio milhão de habitantes, 467.111 (2019), o que representa $5,11 \%$ da população cearense, sob uma extensão territorial de 1.994,907 km² (2018), 1,34\% do território cearense. A média do PIB per Capita é R\$ 14.545,26 (2017), bem abaixo do PIB per Capita estadual ( $R \$ 16.194,60)$, além de um IDHM médio de 0,696 (2010), levemente acima do IDHM do Ceará $(0,682)$ (IBGE, 2020). O de maior adensamento demográfico e maior PIB per Capita é Juazeiro do Norte, considerado o centro econômico da região do Cariri. Crato é o maior em extensão territorial e um dos melhores IDHM do estado, conforme Tabela 1. Ademais, como será evidenciado na análise que se segue, grande parte dos empregos gerados em 2008 e 2018 da RM Cariri concentram na conurbação CRAJUBAR, centro econômico da região e uma importante área estratégica do interior cearense.

Tabela 1: dados sobre os municípios do CRAJUBAR

\begin{tabular}{ccccc}
\hline Município & População (2019) & PIB per capita (2017) & Extensão territorial (2018) & IDHM (2010) \\
\hline Barbalha & 60.781 & $\mathrm{R} \$ 15.488,08$ & $569,508 \mathrm{~km}^{2}$ & 0,683 \\
Crato & 132.123 & $\mathrm{R} \$ 11.772,70$ & $1.176,467 \mathrm{~km}^{2}$ & 0,713 \\
Juazeiro do Norte & 274.207 & $\mathrm{R} \$ 16.375,01$ & $248,832 \mathrm{~km}^{2}$ & 0,694 \\
\hline
\end{tabular}

Fonte: IBGE-Cidades (2020).

Atinente aos grandes setores econômicos, a Tabela 2 mostra a distribuição dos empregos em 2008 e 2018 no CRAJUBAR, na RM Cariri e no Ceará. Em todos os espaços analisados, em 2008, o setor que mais emprega é o de Serviços, representando 58,78\% no estado, 48,74\% na RM Cariri e 44,36\% no CRAJUBAR. Em seguida tem a Indústria, com participação de 19,88\% no estado, $26,52 \%$ na RM Cariri e $29,35 \%$ no CRAJUBAR. Ambos os setores são puxados, sobretudo, por Juazeiro do Norte. O setor do Comércio vem forte, com participação significativa. Os demais setores tem parca participação na geração de empregos. Em 2018, o Comércio está mais visível no mercado de trabalho. O setor de Serviços permanece em primeiro, aumentando sua participação em todos os espaços analisados. Em seguida vem o Comércio, não mais a 
indústria, no estado, na RM Cariri e em Juazeiro do Norte (Barbalha e Crato mantiveram a Indústria na segunda posição, sendo explicado pelo grande aporte calçadista ainda presente e latente nestes municípios com IBK, Kinccal e Grendene S/A).

Tabela 2: empregos formais do CRAJUBAR para os grandes setores econômicos - 2008/2018

\begin{tabular}{|c|c|c|c|c|c|c|c|c|c|c|}
\hline \multirow{2}{*}{ Setores } & \multicolumn{10}{|c|}{2008} \\
\hline & Barbalha & $\%$ & Crato & $\%$ & J. do Norte & $\%$ & RM Cariri & $\%$ & Ceará & $\%$ \\
\hline Indústria & 2.116 & 35,82 & 3.854 & 26,50 & 9.113 & 29,46 & 15.680 & 26,52 & 224.660 & 19,88 \\
\hline Const. Civil & 121 & 2,05 & 119 & 0,82 & 1.051 & 3,40 & 1.733 & 2,93 & 45.715 & 4,05 \\
\hline Comércio & 665 & 11,26 & 3.040 & 20,91 & 8.361 & 27,03 & 12.541 & 21,21 & 169.887 & 15,03 \\
\hline Serviços & 2.959 & 50,09 & 7.431 & 51,10 & 12.406 & 40,10 & 28.823 & 48,74 & 664.227 & 58,78 \\
\hline Agropecuária & 46 & 0,78 & 97 & 0,67 & 6 & 0,02 & 359 & 0,61 & 25.510 & 2,26 \\
\hline Total & 907 & 100,00 & 14.541 & 100,00 & 30.937 & 100,00 & 59.136 & 100,00 & 1.129 .999 & 100,00 \\
\hline \multirow{2}{*}{ Setores } & \multicolumn{10}{|c|}{2018} \\
\hline & Barbalha & $\%$ & Crato & $\%$ & J. do Norte & $\%$ & RM Cariri & $\%$ & Ceará & $\%$ \\
\hline Indústria & 2.469 & 24,72 & 4.429 & 24,03 & 8.030 & 16,16 & 15.633 & 17,76 & 242.769 & 16,50 \\
\hline Const. Civil & 244 & 2,44 & 576 & 3,12 & 1.460 & 2,94 & 2.465 & 2,80 & 56.958 & 3,87 \\
\hline Comércio & 1.813 & 18,15 & 3.841 & 20,84 & 13.004 & 26,17 & 19.575 & 22,23 & 256.392 & 17,42 \\
\hline Serviços & 5.209 & 52,15 & 9.488 & 51,47 & 27.161 & 54,66 & 49.282 & 55,98 & 892.873 & 60,67 \\
\hline Agropecuária & 254 & 2,54 & 99 & 0,54 & 33 & 0,07 & 1.086 & 1,23 & 22.712 & 1,54 \\
\hline Total & 9.989 & 100,00 & 18.433 & 100,00 & 49.688 & 100,00 & 88.041 & 100,00 & 1.471.704 & 100,00 \\
\hline
\end{tabular}

Fonte: elaborado a partir de dados da RAIS (2008-2018).

Analisando o objeto deste trabalho, a Indústria, há um crescimento em termos absolutos no estado, na RM Cariri e nos municípios de Barbalha e Crato, exceção de Juazeiro que auferiu um crescimento significativo no setor de Comércio decorrente da variedade de bens e serviços ofertados, bem como o forte turismo religioso. Em termos relativos, a realidade é outra. Excetuando Barbalha e Crato que, a despeito da queda na participação da Indústria, permanece como 0 segundo setor que mais emprega na região, nos demais ambientes analisados, 0 Comércio cresce vertiginosamente.

Apesar da realidade mostrada acima, a indústria permanece com forte participação no CRAJUBAR, mesmo que a o período analisado demonstre o contrário, conforme se analisa os subsetores industriais na Tabela 3.

Tabela 3: empregos formais do setor industrial no CRAJUBAR por subsetor - 2008/2018

\begin{tabular}{cccccccccccc}
\hline \multirow{3}{*}{ Subsetores Indústria } & \multicolumn{10}{c}{2008} \\
\cline { 2 - 10 } & Barbalha & $\%$ & Crato & $\%$ & J. do Norte & $\%$ & RM Cariri & $\%$ & Ceará & $\%$ \\
\hline Extrativa Mineral & 30 & 1,42 & 54 & 1,40 & 48 & 0,53 & 416 & 2,65 & 2.600 & 1,16
\end{tabular}




\begin{tabular}{|c|c|c|c|c|c|c|c|c|c|c|}
\hline Prod. Mineral Não Met. & 274 & 12,95 & 502 & 13,03 & 163 & 1,79 & 1.123 & 7,16 & 9.976 & 4,44 \\
\hline Indústria Metalúrgica & 9 & 0,43 & 228 & 5,92 & 755 & 8,28 & 1.012 & 6,45 & 11.395 & 5,07 \\
\hline Indústria Mecânica & 10 & 0,47 & 6 & 0,16 & 523 & 5,74 & 539 & 3,44 & 3.831 & 1,71 \\
\hline Elétrico e Comunic. & 0 & 0,00 & 0 & 0,00 & 0 & 0,00 & 0 & 0,00 & 2.278 & 1,01 \\
\hline Material de Transporte & 89 & 4,21 & 1 & 0,03 & 16 & 0,18 & 106 & 0,68 & 3.000 & 1,34 \\
\hline Madeira e Mobiliário & 29 & 1,37 & 53 & 1,38 & 125 & 1,37 & 210 & 1,34 & 6.614 & 2,94 \\
\hline Papel e Gráf. & 9 & 0,43 & 194 & 5,03 & 153 & 1,68 & 356 & 2,27 & 7.004 & 3,12 \\
\hline Borracha, Fumo, Couros & 204 & 9,64 & 27 & 0,70 & 1.323 & 14,52 & 1.554 & 9,91 & 6.626 & 2,95 \\
\hline Indústria Química & 667 & 31,52 & 213 & 5,53 & 320 & 3,51 & 1.208 & 7,70 & 11.498 & 5,12 \\
\hline Indústria Têxtil & 95 & 4,49 & 138 & 3,58 & 568 & 6,23 & 811 & 5,17 & 62.706 & 27,91 \\
\hline Indústria Calçados & 561 & 26,51 & 2.114 & 54,85 & 3.899 & 42,79 & 6.574 & 41,93 & 49.832 & 22,18 \\
\hline Alimentos e Bebidas & 137 & 6,47 & 278 & 7,21 & 951 & 10,44 & 1.402 & 8,94 & 40.782 & 18,15 \\
\hline Serviço Util. Pública & 2 & 0,09 & 46 & 1,19 & 269 & 2,95 & 369 & 2,35 & 6.518 & 2,90 \\
\hline Total & 2.116 & 100,00 & 3.854 & 100,00 & 9.113 & 100,00 & 15.680 & 100,00 & 224.660 & 100,00 \\
\hline \multirow{2}{*}{ Subsetores Indústria } & \multicolumn{10}{|c|}{2018} \\
\hline & Barbalha & $\%$ & Crato & $\%$ & J. do Norte & $\%$ & RM Cariri & $\%$ & Ceará & $\%$ \\
\hline Extrativa Mineral & 4 & 0,16 & 50 & 1,13 & 9 & 0,11 & 177 & 1,13 & 2.835 & 1,17 \\
\hline Prod. Mineral Não Met. & 55 & 2,23 & 590 & 13,32 & 395 & 4,92 & 1.458 & 9,33 & 11.103 & 4,57 \\
\hline Indústria Metalúrgica & 21 & 0,85 & 264 & 5,96 & 639 & 7,96 & 966 & 6,18 & 12.683 & 5,22 \\
\hline Indústria Mecânica & 0 & 0,00 & 7 & 0,16 & 193 & 2,40 & 201 & 1,29 & 8.016 & 3,30 \\
\hline Elétrico e Comunic. & 6 & 0,24 & 0 & 0,00 & 9 & 0,11 & 15 & 0,10 & 3.250 & 1,34 \\
\hline Material de Transporte & 30 & 1,22 & 0 & 0,00 & 26 & 0,32 & 56 & 0,36 & 2.988 & 1,23 \\
\hline Madeira e Mobiliário & 49 & 1,98 & 23 & 0,52 & 237 & 2,95 & 377 & 2,41 & 6.986 & 2,88 \\
\hline Papel e Gráf. & 3 & 0,12 & 231 & 5,22 & 207 & 2,58 & 444 & 2,84 & 7.668 & 3,16 \\
\hline Borracha, Fumo, Couros & 1 & 0,04 & 19 & 0,43 & 1.109 & 13,81 & 1.129 & 7,22 & 5.337 & 2,20 \\
\hline Indústria Química & 1.341 & 54,31 & 68 & 1,54 & 649 & 8,08 & 2.063 & 13,20 & 11.318 & 4,66 \\
\hline Indústria Têxtil & 96 & 3,89 & 22 & 0,50 & 356 & 4,43 & 486 & 3,11 & 55.566 & 22,89 \\
\hline Indústria Calçados & 729 & 29,53 & 2.304 & 52,02 & 2.113 & 26,31 & 5.146 & 32,92 & 57.227 & 23,57 \\
\hline Alimentos e Bebidas & 134 & 5,43 & 730 & 16,48 & 1.295 & 16,13 & 2.192 & 14,02 & 48.432 & 19,95 \\
\hline Serviço Util. Pública & 0 & 0,00 & 121 & 2,73 & 793 & 9,88 & 923 & 5,90 & 9.360 & 3,86 \\
\hline Total & 2.469 & 100,00 & 4.429 & 100,00 & 8.030 & 100,00 & 15.633 & 100,00 & 242.769 & 100,00 \\
\hline
\end{tabular}

Fonte: elaborado a partir de dados da RAIS (2008-2018).

A Tabela 3 apresenta a oferta de empregos por subsetor da Indústria para o Ceará, RM Cariri e CRAJUBAR em 2008 e 2018. Nela observa-se que os subsetores que mais empregaram 
no estado em 2008 foram a indústria têxtil $(27,91 \%)$, indústria de calçados $(22,18 \%)$ e alimento e bebidas $(18,15 \%)$, sendo que estas representam conjuntamente $68,24 \%$ do emprego industrial no referido ano. Para a RM Cariri, os subsetores mais empregadores são a indústria de calçados $(41,93 \%)$, borracha, fumo e couros $(9,91 \%)$ e alimento e bebidas (8,94\%). A indústria têxtil não é tão expressiva nesta região pois se concentra principalmente na RMF. As demais atividades expressam o forte papel dos calçados e derivados (caracterizando o estado como um três dos polos calçadistas mais importantes do país) e das fabricantes de alimentos e bebidas presentes em todo o estado. Em relação ao CRAJUBAR, os subsetores mais expressivos são a indústria de calçados $(43,59 \%)$, borracha, fumo e couros $(10,30 \%)$ e alimentos e bebidas $(9,06 \%)$. A expressão do setor calçadista na região já citada, expressa a importância econômica da região. $O$ segundo subsetor descrito auxilia o primeiro subsetor dentro da RM Cariri e CRAJUBAR. Em relação aos municípios, Crato e Juazeiro do Norte possuem $54,85 \%$ e $42,79 \%$ dos empregos advindos da indústria calçadista. Para Barbalha, o subsetor que mais emprega é a indústria química, representando $31,52 \%$ no município e $55,58 \%$ no CRAJUBAR e 55,21\% na RM Cariri. Fator de destaque na região, que se amplia em 2018 conforme segue a análise.

Em 2018, no Ceará, os subsetores que mais empregaram são os mesmo de 2008, com a diferença que a indústria de calçados assume o posto de primeiro subsetor que mais gera empregos (23,57\% do total), seguido pela indústria têxtil (22,89\%). Na RM Cariri, a indústria tem queda absoluta e relativa, porém, permanece em primeiro lugar $(32,92 \%)$, seguida agora pela indústria química $(13,20 \%)$ puxada, sobretudo, por Barbalha. Na terceira posição vem a indústria de alimento e bebidas (14,02\%). Borracha, fumo e couros cai vertiginosamente em relação a 2008 , acompanhando a queda na produção de calçados. Para o CRAJUBAR, os subsetores mais expressivos são indústria calçadista $(34,47 \%)$, alimentos e bebidas $(14,46 \%)$ e indústria química $(13,79 \%)$. Esse cenário indica queda absoluta e relativa do subsetor industrial mais empregador, porém permanecendo como principal da região. A indústria química cresceu rapidamente entre 2008 e 2018 principalmente pelas atividades presentes em Barbalha que detém 65,16\% da oferta do CRAJUBAR, $64,84 \%$ na RM Cariri, e o mais destacável, $11,85 \%$ da oferta deste subsetor em todo 0 estado, graças a atividade farmacêutica da Farmace (Indústria Químico Farmacêutica Cearense Ltda.). Em Crato, a atividade industrial permanece no topo da oferta de trabalho, gerando mais de $50 \%$ do total, sendo explicada pela presença da Grendene S/A. Juazeiro do Norte apresenta uma dinâmica mais variada com três subsetores importantes: a indústria calçadista $(26,31 \%)$, alimentos e bebidas $(16,13 \%)$ e borracha, fumo e couros $(13,81 \%)$.

Tabela 4: empregos formais do setor industrial no CRAJUBAR para o sexo - 2008/2018 


\begin{tabular}{|c|c|c|c|c|c|}
\hline Município & Sexo & 2008 & $\%$ & 2018 & $\%$ \\
\hline & Masculino & 1.584 & 74,86 & 1.783 & 72,22 \\
\hline \multirow[t]{3}{*}{ Barbalha } & Feminino & 532 & 25,14 & 686 & 27,78 \\
\hline & Total & 2.116 & 100,00 & 2.469 & 100,00 \\
\hline & Masculino & 2.652 & 68,81 & 3.025 & 68,30 \\
\hline \multirow[t]{3}{*}{ Crato } & Feminino & 1.202 & 31,19 & 1.404 & 31,70 \\
\hline & Total & 3.854 & 100,00 & 4.429 & 100,00 \\
\hline & Masculino & 6.367 & 69,87 & 5.773 & 71,89 \\
\hline \multirow[t]{3}{*}{ Juazeiro do Norte } & Feminino & 2.746 & 30,13 & 2.257 & 28,11 \\
\hline & Total & 9.113 & 100,00 & 8.030 & 100,00 \\
\hline & Masculino & 11.153 & 71,13 & 11.235 & 71,87 \\
\hline \multirow[t]{3}{*}{ RM Cariri } & Feminino & 4.527 & 28,87 & 4.398 & 28,13 \\
\hline & Total & 15.680 & 100,00 & 15.633 & 100,00 \\
\hline & Masculino & 140.258 & 62,43 & 155.954 & 64,24 \\
\hline \multirow[t]{2}{*}{ Ceará } & Feminino & 84.402 & 37,57 & 86.815 & 35,76 \\
\hline & Total & 224.660 & 100,00 & 242.769 & 100,00 \\
\hline
\end{tabular}

Fonte: elaborado a partir de dados da RAIS (2008-2018).

No que se refere ao sexo (Tabela 4) do(a) trabalhador(a), no Ceará o sexo masculino tem maior participação dos empregos industriais tanto em 2008 quanto em 2018, com leve queda na participação relativa da mulher, como demonstrado em trabalhos anteriores como 0 de Alves, Pereira e Lima Junior (2019), mas com aumento absoluto em ambos os sexos. Na RM Cariri, a concentração no sexo masculino é maior do que no estado, com leve redução da participação da mulher em termos absolutos e relativos, chegando a mais de 70\%. No CRAJUBAR, o sexo masculino tem participação de 70,08\% e 70,04\% em 2008 e 2018, respectivamente, evidenciando a forte concentração dos homens no setor industrial. Em Barbalha e Crato, o sexo feminino auferiu leve crescimento na participação (25,14\% e 27,78\% em Barbalha e 31,19\% e 31,70\% em Crato para 2008 e 2018), mas ainda sim o sexo masculino permanece com maior participação, sobretudo em Barbalha. Juazeiro do Norte que teve redução do emprego industrial nos anos analisados, teve queda na participação das mulheres na indústria. Em suma, ainda há forte concentração do sexo masculino na indústria, com a mulher perdendo espaço neste setor, com exceção de Barbalha e Crato. Portanto, o componente de gênero permanece atuando na desvalorização da mão de obra feminina, merecendo mais atenção, debates e estudos sobre essa questão, não somente na área de estudo deste trabalho, mas em todo o país, com o intuito de buscar a igualdade de gênero e reduzir as desigualdades de renda e oportunidades.

Tabela 5: empregos formais do setor industrial no CRAJUBAR para o grau de instrução 2008/2018 


\begin{tabular}{|c|c|c|c|c|c|}
\hline & Grau de Instrução & 2008 & $\%$ & 2018 & $\%$ \\
\hline & Sem instrução até fund. Inc. & 292 & 13,80 & 216 & 8,75 \\
\hline & Fund. compl. até méd. inc. & 499 & 23,58 & 404 & 16,36 \\
\hline \multirow[t]{7}{*}{ Barbalha } & Médio completo até sup. inc. & 1.229 & 58,08 & 1.677 & 67,92 \\
\hline & Superior completo & 96 & 4,54 & 167 & 6,76 \\
\hline & Mestrado e Doutorado & 0 & 0,00 & 5 & 0,20 \\
\hline & Total & 2.116 & 100,00 & 2.469 & 100,00 \\
\hline & Grau de Instrução & 2008 & $\%$ & 2018 & $\%$ \\
\hline & Sem instrução até fund. inc. & 1.019 & 26,44 & 551 & 12,44 \\
\hline & Fund. compl. até méd. inc. & 969 & 25,14 & 780 & 17,61 \\
\hline \multirow[t]{7}{*}{ Crato } & Médio completo até sup. inc. & 1.787 & 46,37 & 2.872 & 64,85 \\
\hline & Superior completo & 79 & 2,05 & 220 & 4,97 \\
\hline & Mestrado e Doutorado & 0 & 0,00 & 6 & 0,14 \\
\hline & Total & 3.854 & 100,00 & 4.429 & 100,00 \\
\hline & Grau de Instrução & 2008 & $\%$ & 2018 & $\%$ \\
\hline & Sem instrução até fund. inc. & 1.641 & 18,01 & 922 & 11,48 \\
\hline & Fund. compl. até méd. inc. & 2.632 & 28,88 & 1.581 & 19,69 \\
\hline \multirow[t]{7}{*}{ Juazeiro do Norte } & Médio completo até sup. inc. & 4.662 & 51,16 & 5.203 & 64,79 \\
\hline & Superior completo & 171 & 1,88 & 319 & 3,97 \\
\hline & Mestrado e Doutorado & 7 & 0,08 & 5 & 0,06 \\
\hline & Total & 9.113 & 100,00 & 8.030 & 100,00 \\
\hline & Grau de Instrução & 2008 & $\%$ & 2018 & $\%$ \\
\hline & Sem instrução até fund. inc. & 3.273 & 20,87 & 1.920 & 12,28 \\
\hline & Fund. compl. até méd. inc. & 4.266 & 27,21 & 3.013 & 19,27 \\
\hline \multirow[t]{7}{*}{ RM Cariri } & Médio completo até sup. inc. & 7.783 & 49,64 & 9.971 & 63,78 \\
\hline & Superior completo & 351 & 2,24 & 712 & 4,55 \\
\hline & Mestrado e Doutorado & 7 & 0,04 & 17 & 0,11 \\
\hline & Total & 15.680 & 100,00 & 15.633 & 100,00 \\
\hline & Grau de Instrução & 2008 & $\%$ & 2018 & $\%$ \\
\hline & Sem instrução até fund. inc. & 47.368 & 21,08 & 28.706 & 11,82 \\
\hline & Fund. compl. até méd. inc. & 71.960 & 32,03 & 47.367 & 19,51 \\
\hline \multirow[t]{4}{*}{ Ceará } & Médio completo até sup. inc. & 97.867 & 43,56 & 151.126 & 62,25 \\
\hline & Superior completo & 7.102 & 3,16 & 15.146 & 6,24 \\
\hline & Mestrado e Doutorado & 363 & 0,16 & 424 & 0,17 \\
\hline & Total & 224.660 & 100,00 & 242.769 & 100,00 \\
\hline
\end{tabular}

Fonte: elaborado a partir de dados da RAIS (2008-2018).

Atinente ao grau de instrução, no estado é visível, a partir da Tabela 5, o melhoramento no grau de escolaridade dos trabalhadores da indústria entre 2008 e 2018, com redução significativa dos graus sem instrução até fundamental incompleto (redução de 39,39\%) e do Fundamental completo até o médio incompleto (redução de 34,17\%) e aumento significativo dos graus mais elevados, sobretudo o ensino superior completo em termos relativos (aumento de 
113,26\%). A maior participação dar-se pelos trabalhadores com ensino médio completo até superior incompleto (crescimento de 54,42\%). Para a RM Cariri, a tendência segue a mesma do estado com maior participação na indústria dos que possuem médio completo até superior completo $(49,64 \%$ e 63,78\% em 2008 e 2018, respectivamente, representando aumento de $28,11 \%)$. No CRAJUBAR, a realidade permanece a do estado. Já em 2008 a faixa de escolaridade supracitada já representava 50,90\% dos empregos gerados. Em 2018, a despeito da queda na oferta de emprego industrial, a participação cresce 15 pontos percentuais, passando para 65,33\%. Destaque para o CRAJUBAR, RM Cariri e Ceará a mencionada redução dos empregos de baixa escolaridade e aumento, ainda que baixo, de empregos com alto grau de escolaridade. A concentração dos empregos nessa faixa de instrução ocorre em todos os municípios dessa conurbação (superando os 64\%), na qual a maior parte da oferta de oportunidades está em Juazeiro do Norte (53,79 em 2018), cidade polo da RM Cariri.

Tabela 6: empregos formais do setor industrial no CRAJUBAR para faixa salarial - 2008/2018

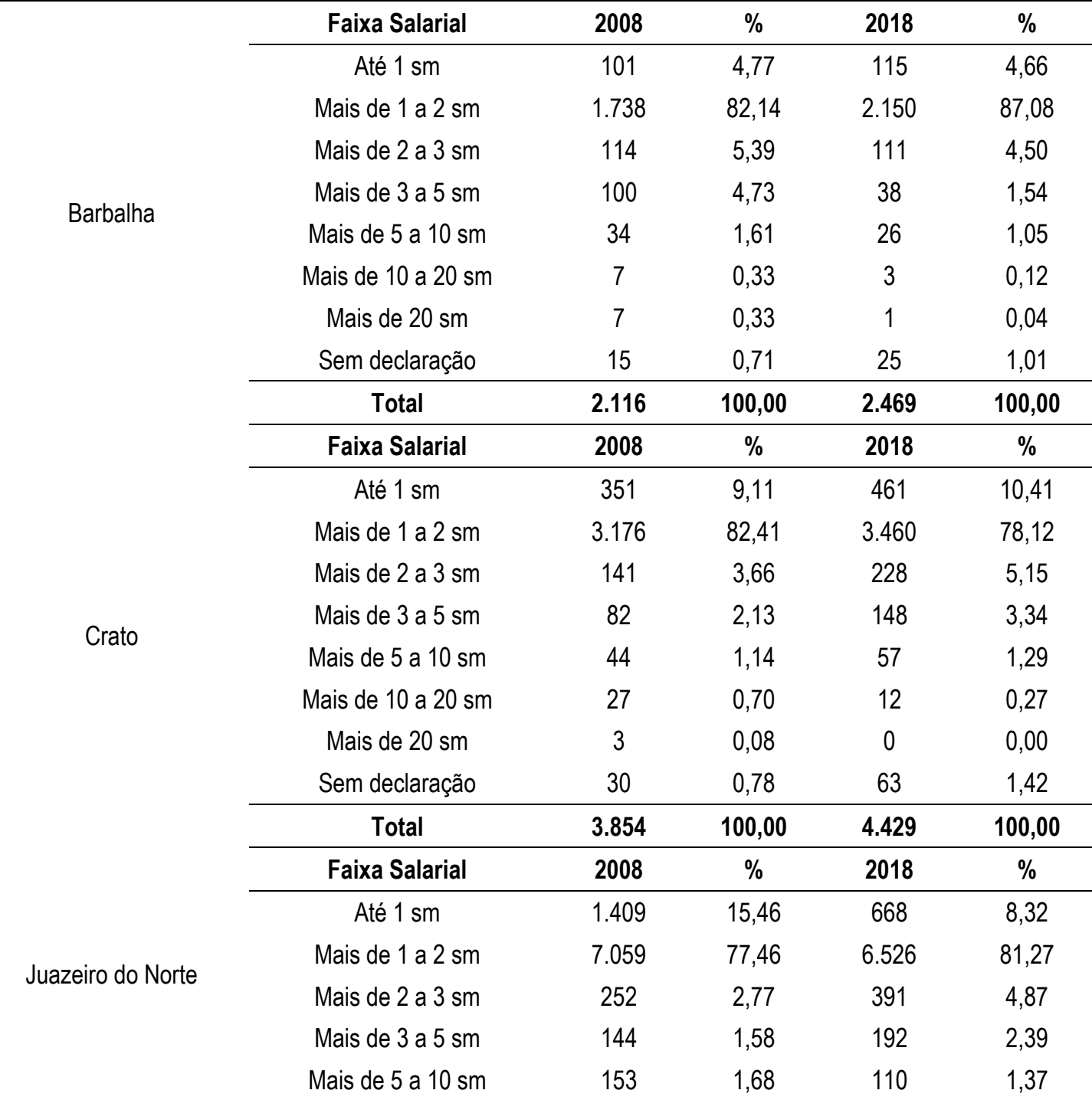




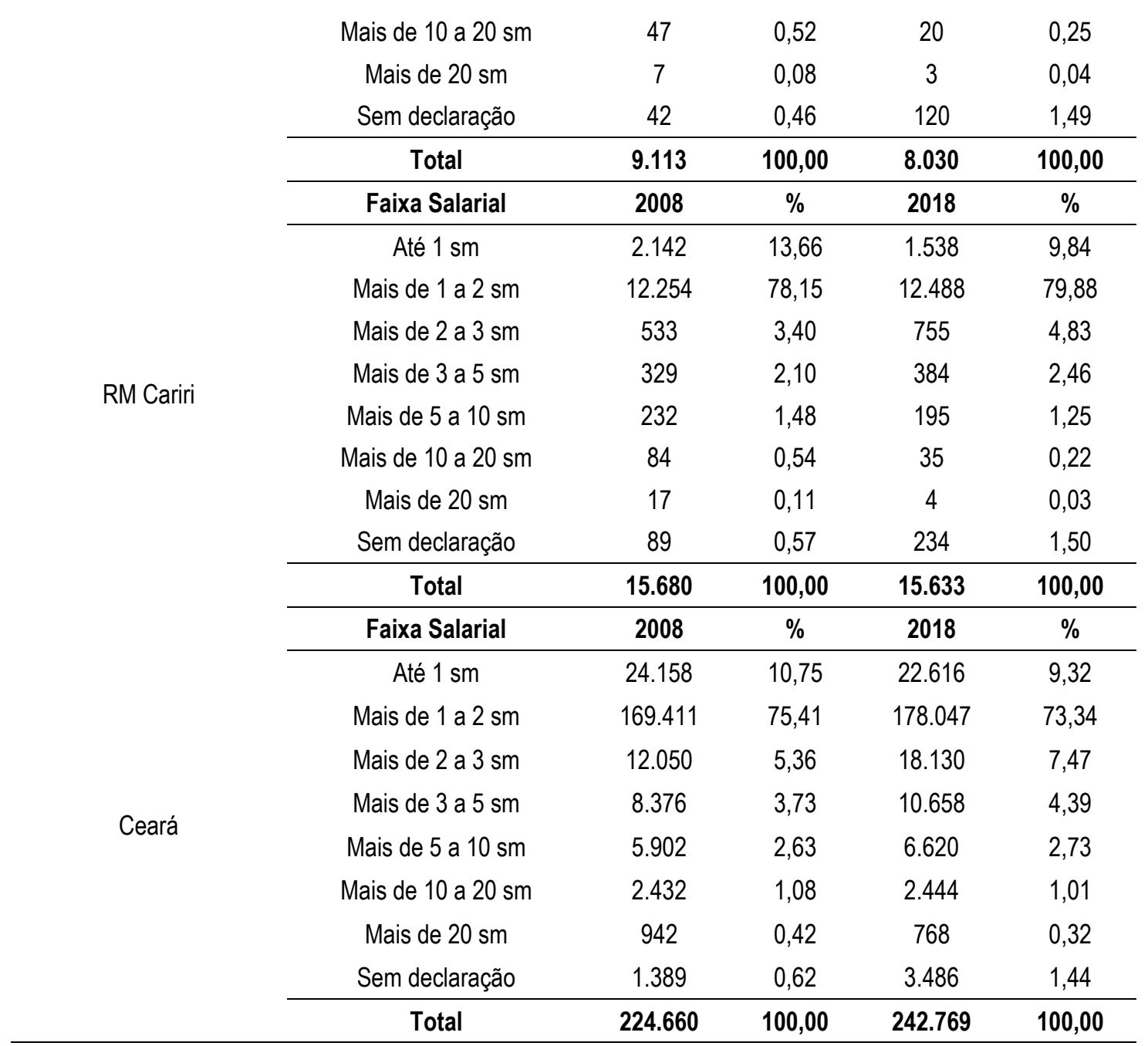

Fonte: elaborado a partir de dados da RAIS (2008-2018).

No que se refere a faixa salarial, em 2008 e 2018, o Ceará tem a faixa de mais de 1 a 2 sm para mais de $70 \%$ dos(as) trabalhadores(as). Na RM Cariri e no CRAJUBAR a tendência segue a mesma do estado, tendo a faixa de mais de 1 a $2 \mathrm{sm}$ como a faixa que mais remunera, com mais de $70 \%$ (perto dos $80 \%$ ) da remuneração dos postos de trabalho ofertados pela indústria, mostrando ainda o baixo nível salarial neste setor, a despeito da leve melhora evidenciada em 2018. No CRAJUBAR, mais de $81 \%$ da mão de obra recebe mais de 1 a $2 \mathrm{sm}$. A concentração nesta faixa salarial é mais evidente em Barbalha (de 82,14\% em 2008 para 87,08\% em 2018) e a menor concentração está em Crato (de 82,41\% em 2008 para 78,12\% em 2018), porém, neste município, houve aumento nas vagas com remuneração de até $1 \mathrm{sm}$. Ademais houve aumento nas não declarações de faixa salarial dentro dos anos analisados. Por fim, destaca-se que as faixas de mais de 2 a $3 \mathrm{sm}$ e de mais 3 a $5 \mathrm{sm}$ cresceram em todos os anos e área de estudo analisadas neste trabalho.

Quanto à faixa etária, o que se observa em 2008 é a faixa entre 25 e 39 anos preenchendo em mais de 50\% das vagas do setor industrial no estado, RM Cariri e CRAJUBAR. Em 2018, em 
termos absolutos, excetuando Barbalha, a faixa preponderante reduziu o número de postos de trabalho. Em termos relativos, o CRAJUBAR e seus componentes tiveram queda percentual dentro das faixas salariais na Indústria (Barbalha, mesmo com queda na participação relativa, auferiu mais postos de trabalho para a faixa de 25 a 39 anos).

De acordo com os dados expostos acima, há um fato em debate que se apresenta não só na realidade de Barbalha, Crato e Juazeiro do Norte, mas em todo o Brasil: overeducation (quando o grau de instrução do(a) trabalhador(a) é superior ao exigido pelo seu emprego) e undereducation (quando o grau de instrução do(a) trabalhador(a) é inferior ao exigido pelo seu emprego, podendo ser explicado pela questão da experiência ou pela própria formação do trabalho) (DIAZ; MACHADO, 2008; ANNEGUES et al., 2018).

\section{CONSIDERAÇÕES FINAIS}

A trajetória da industrialização brasileira nasce nos anos 1930, com a grande depressão de 1929 e o consequente deslocamento do centro dinâmico. As ações intervencionistas do Governo Federal agiram positivamente na consolidação da indústria no país, com a criação de diversas estatais, sobretudo nos anos de industrialização pesada (1956-70) iniciada por JK através de investimentos nacionais, estrangeiros e estatais. Com a presença dos debates sobre desigualdades regionais encabeçadas pela CEPAL, Celso Furtado coordena ações através da SUDENE de políticas de planejamento regional que possibilitassem ao Nordeste se desenvolver e atingir níveis industriais significativos.

A região Nordeste, diferentemente da realidade nacional, apresentou bom desempenho no emprego industrial pela relocalização espacial industrial e aos efeitos dos incentivos fiscais para atrair as indústrias. Nesse contexto, Bahia, Ceará e Pernambuco se destacam. 0 segundo estado em questão auferiu um complexo industrial a partir da "Era das Mudanças" na década de 1980, envolto pelo ideário neoliberal e modernista iniciado na época. A RM Cariri, localizada no sul do estado, ganha destaque pelas políticas de desconcentração demográfica e econômica promovidas pelo governo estadual. Destarte, o CRAJUBAR, centro econômico da região, tornouse um dos polos de desenvolvimento inter-regional do Nordeste com influência considerável que ultrapassa os limites territoriais, atingindo outros estados como o Piauí, Pernambuco e a Paraíba.

Quanto aos resultados, mais de $90 \%$ da produção e fluxo de mão de obra da RM Cariri está em volta do triângulo CRAJUBAR. A Indústria apresenta forte dinamismo na geração de empregos e produção, sobretudo a indústria calçadista (este setor tem forte presença no estado, configurando o Ceará com um dos três setores mais importantes tanto para o mercado interno 
quanto para o externo pelo fácil escoamento para as outras Américas e Europa por Fortaleza) em Barbalha e Crato. Em Juazeiro do Norte o referido setor perde espaço pela diversidade produtiva e ascensão do setor de Comércio nos anos analisados. Os subsetores que mais se destacam são a indústria de calçados (43,59\%), borracha, fumo e couros (10,30\%) e alimentos e bebidas $(9,06 \%)$ em 2008 e indústria calçadista (34,47\%), alimentos e bebidas (14,46\%) e indústria química $(13,79 \%)$ (a presença da indústria química reforça o setor farmacêutico presente principalmente em Barbalha).

Quanto ao perfil da mão de obra industrial, há forte concentração do sexo masculino na indústria, com a mulher perdendo espaço, com exceção de Barbalha e Crato. Portanto, o componente de gênero permanece atuando na desvalorização da mão de obra feminina, merecendo mais atenção, debates e estudos sobre essa questão, não somente na área de estudo deste trabalho, mas em todo o país, com o intuito de buscar a igualdade de gênero e reduzir as desigualdades de renda e oportunidades. A faixa de escolaridade concentra-se em mais de $50 \%$ em 2008 e mais de 65\% em 2018 para aqueles que possuem ensino médio completo até superior incompleto. Destaque para a melhoria nos níveis educacionais da região, destacando o papel das IES. A faixa salarial está para mais de 1 a 2 sm (mais de $70 \%$ dos(as) trabalhadores(as)) em 2008 e 2018. Para este ano, os números são mais concentrados, ficando para essa faixa em mais de $81 \%$. A faixa etária que mais é empregada na indústria está entre 25 e 39 anos preenchendo em mais de $50 \%$ das vagas do setor.

Em suma, apesar de melhorar alguns dos indicadores, como o aumento dos postos de trabalho dentro de um período de crise (desde 2014), há um hiato entre os níveis de escolaridade e faixa salarial evidenciados neste trabalho, de modo que os níveis de educação melhoraram, porém grande parte dos empregos ofertados é para aqueles que estejam no máximo cursando alguma graduação. Esse hiato (seja overeducation ou undereducation) está presente na realidade do mercado de trabalho, pela incorporação de pessoas com qualificações que não condizem com o posto de trabalho que ocupa. Ademais, persiste a reduzida participação das mulheres no setor industrial e que continua a cair.

Dessa forma, conclui-se que o perfil de mão de obra do setor industrial do CRAJUBAR apresenta melhor nível educacional, porém em postos de trabalho que não condizem com sua realidade escolar, com baixa participação das mulheres, as quais ainda encontram desafios para tentar igualar as remunerações com a classe masculina, enfrentando barreiras frente a ascensão profissional ganhando menos que os homens, mesmo quando ocupam cargos equivalentes, com mais tempo de experiência profissional, estudo e enfrentam a mesma carga horária. 


\section{REFERÊNCIAS BIBLIOGRÁFICAS}

ALVES, D. F.; PEREIRA, W. E. N.; LIMA JUNIOR, F. do O' de. A participação da mulher no mercado formal de trabalho industrial cearense: comparativo entre os anos de 2006 e 2014. Revista Ciências do Trabalho, n. 13, p. 17-40, 2019.

AMORA. Z. B. Indústria e espaço no Ceará. In. SILVA, J. B. da, CAVALCANTE, T. C. e DANTAS, E.W. C. (org.) Ceará: um novo olhar geográfico. $2^{\mathrm{a}}$ ed. Fortaleza: Edições Demócrito Rocha, 2007.

ANNEGUES, A. C. et al. Overeducation e Área de Formação: evidências para os Egressos da UFPB. In: XXIII Encontro Regional de Economia - ANPEC Nordeste. Anais... Fortaleza-CE, 2018.

ANTUNES, R. Os sentidos do trabalho: ensaio sobre a afirmação e a negação do trabalho. $2^{\mathrm{a}}$ ed. São Paulo: Boitempo, 2009.

ARAUJO, E. A. dos S. Turismo Sustentável: o Geopark Araripe no contexto do desenvolvimento da Região Metropolitana do Cariri. 104 p. Monografia (Graduação em Ciências Econômicas). Universidade Regional do Cariri, Crato-CE, 2018.

ARAUJO, M. de L. de. A Cidade do Padre Cícero: trabalho e fé. 259 p. Tese (Doutorado em Planejamento Urbano e Regional), Universidade Federal do Rio de Janeiro, Rio de Janeiro, 2005.

ARAÚJO, N. de G. A industrialização no Ceará: breves considerações. Boletim Goiano de Geografia, v. 27, n. 2, p. 97-113, 2007.

ARAUJO, T. B. A "questão regional" e a "questão nordestina". In: TAVARES, M. da C. (org.).

Celso Furtado e o Brasil, 2000.

ARRUDA, G. C. M. et al. Política de emprego no estado do Ceará. In: POSTHUMA, A. C. (org.). Abertura e ajuste do mercado de trabalho no Brasil: políticas para conciliar os desafios de emprego e competitividade. OIT e MTE. São Paulo: Ed. 34, 1999.

BATISTA, J. C. A estratégia de ajustamento externo do Segundo Plano Nacional de Desenvolvimento. Revista de Economia Política, v. 7, n. 2, p. 66-80, 1987.

BESERRA, F. R. S. Reestruturação do capital e indústria calçadista na Região do Cariri-CE.

Revista RA'EGA, n. 18, p. 89-101, 2009.

BESERRA, F. R. S. Espaço, indústria e reestruturação do capital: a indústria de calçados na Região do Cariri-CE. 132 f. Dissertação (Mestrado em Geografia), Universidade Estadual do Ceará, Fortaleza, 2007.

BESERRA, F. R. S. O processo de industrialização do Cariri e o papel do Estado rumo a uma modernização conservadora. In: I Encontro internacional de trabalho e perspectivas de formação dos trabalhadores. LABOR/UFC. 2006.

CANO, W. Da Década de 1920 à de 1930: Transição Rumo à Crise e à Industrialização no Brasil Revista EconomiA, v. 13, n. 3b, p. 897-916, 2012.

CANO, W. Desequilíbrios regionais e concentração industrial no Brasil 1930-1970. $3^{\mathrm{a}} \mathrm{ed}$.

São Paulo: Editora UNESP, 2007.

CANO, W. Raízes da concentração industrial em São Paulo. São Paulo: Difel, 1977.

CAPUTO, A. C.; MELO, H. P. de. A industrialização brasileira nos anos de 1950: uma análise da instrução 113 da SUMOC. Estudos Econômicos, São Paulo, v. 39, n. 3, p. 513-538, 2009.

CARLEIAL, L. Avaliação da política industrial do Ceará: uma contribuição ao debate. Fortaleza: IEL/FIEC, 1983.

CARVALHO, C. P. de O. O Desenvolvimento da Região Nordeste nos Anos Pós-Sudene (20002016). Revista Paranaense de Desenvolvimento, v. 39, n. 134, p. 21-36, 2018. 
CORDEIRO, R. de M. As aglomerações produtivas de calçados, folheados e de joias do CRAJUBAR (CE): formação, produção, trabalho, implicações socioespaciais. $326 \mathrm{f}$. Tese (Doutorado em Geografia), Universidade Estadual Paulista, São Paulo, 2015.

DIAZ, M. D. M.; MACHADO, L. Overeducation e undereducation no Brasil: incidência e retornos. Estudos Econômicos, São Paulo, v. 38, n. 3, p. 431-460, 2008.

ELIAS, D.; SAMPAIO, J. L. F. Modernização Excludente. Fortaleza: Edições Demócrito Rocha, 2002.

FISHLOW, A. Origens e consequências da substituição de importações no Brasil. Estudos Econômicos, São Paulo, v. 2, n. 6, p. 7-75, 1972.

FURTADO, C. Formação Econômica do Brasil. $32^{a}$ Edição. São Paulo: Companhia Editora Nacional, 2005.

KERECKI, M.; SANTOS, M. dos. Programa de Ação Econômica do Governo (PAEG): do milagre econômico ao fim do sonho. Revista Historiador, v. 2, p. 183-188, 2009.

LIMA JÚNIOR, F. do O' de. Macro contexto contemporâneo e transformações econômicas: os ajustes espaciais cearenses. Geosul, Florianópolis, v. 34, n. 70, p. 195-219, 2019.

LIMA JUNIOR, F. do O' de. SUDENE e forças sociais nordestinas. Crato-CE: RDS, 2014a. LIMA JUNIOR, F. do O' de. Estrutura produtiva e rede urbana no estado do Ceará durante o período de 1980-2010. 264 p. Tese (Doutorado em Desenvolvimento Econômico), Universidade Estadual de Campinas, Campinas, 2014b.

LIMA JÚNIOR, F. do O' de. As espacialidades intra-urbanas e a dinâmica econômica nas cidades médias sul cearenses. In: XIII Simpósio Nacional de Geografia Urbana. Anais... Rio de Janeiro, 2013.

LIMA JUNIOR, F. do O' de; MACEDO, F. C. de. A constituição da rede urbana sul cearense: aspectos de sua formação e distinções contemporâneas. In: MORAIS, J. M. L.; MACEDO, F. C. de; LIMA JUNIOR, F. do O' de. (org.) Ceará: economia, urbanização e metropolização. CratoCE: RDS, 2014.

MINISTÉRIO DA ECONOMIA. DEST 30 anos, 2015. Disponível em: <http://www.planejamento.gov.br/assuntos/empresas-estatais/coordenacao/historico>. Acesso em 25 de fevereiro de 2020.

OLIVEIRA, A. A. O Cariri Cearense: da ocupação do território à institucionalização da Região Metropolitana do Cariri. 135 p. Dissertação (Mestrado em Economia), Universidade Federal do Rio Grande do Norte, Natal, 2014.

OLIVEIRA, A. A.; APOLINÁRIO, V.; PEREIRA, W. E. N. A política de industrialização do Ceará e suas repercussões no mercado formal de trabalho industrial: analise do polo CRAJUBAR para os anos de 1990 a 2010. Revista de economia regional, urbana e do trabalho, v. 2, n. 1, p. 3247, 2013.

PEREIRA JUNIOR, E. A industrialização como vetor de modernização econômica: abordagens sobre o espaço industrial no Ceará. Revista Paranaense de Desenvolvimento, n. 123, p. $117-$ 134, 2012.

PRODANOV, C. C.; FREITAS, E. C. de. Metodologia do trabalho científico: métodos e técnicas da pesquisa e do trabalho acadêmico $2^{\mathrm{a}}$ ed. Novo Hamburgo: Feevale, 2013. REDWOOD, J. Incentivos fiscais, empresas extraregionais e a industrialização recente do Nordeste brasileiro. Estudos Econômicos 14 (1): p. 119-143, 1984.

SALLES FILHO, S. Política de Ciência e Tecnologia no I PND (1972/74) e no I PBDCT (1973/74). Revista brasileira de inovação, v. 1, n. 2, p. 397-419, 2002.

SALOMAO, I. Do estrangulamento externo à moratória: a negociação brasileira com o FMI no Governo Figueiredo (1979-1985). Revista economia contemporânea, v. 20, n. 1, p. 5-27, 2016. 
UNESCO. Geoparque Mundial Araripe (Brasil), 2020. Disponível em:

$<$ http://www.unesco.org/new/pt/brasilia/natural-sciences/environment/earth-sciences andgeoparks/araripe-unesco-global-geopark/>. Acesso em 23 de fevereiro de 2020.

VERSIANI, F. R.; VERSIANI, M. T. R. O. A industrialização brasileira antes de 1930: uma contribuição. Estudos Econômicos, São Paulo, v. 5, n. 1, p. 37-63, 1975.

\title{
Recebido para avaliação em Maio de 2020. \\ Aceito para Publicação em Setembro de 2020. \\ O SETOR INDUSTRIAL E SEUS EFEITOS NO MERCADO DE TRABALHO FORMAL: UMA ANÁLISE PARA O TRIÂNGULO CRAJUBAR-CE (2008-2018)
}

Resumo: Este trabalho objetiva analisar o mercado de trabalho formal sob a ótica do setor industrial no CRAJUBAR para os anos 2008 e 2018, evidenciando o panorama da economia da região via indústria, bem como as repercussões sobre a institucionalização da RM Cariri, em 2009. A metodologia utilizada é de caráter exploratório. O meio técnico utilizado foi o estatístico. Tem-se como área de pesquisa o triângulo CRAJUBAR, formado pelos municípios Crato, Juazeiro do Norte e Barbalha, tendo como foco de análise o setor industrial formal. Faz-se uso de microdados, referentes aos anos de 2008 e 2018, provenientes do banco de dados da RAIS/MTE e do IBGE. Conclui-se que o perfil de mão de obra do setor industrial apresenta melhor nível educacional, porém em postos de trabalho que não condizem com sua realidade escolar, com baixa participação das mulheres, as quais ainda encontram desafios na tentativa de igualar as remunerações com a classe masculina.

Palavras-chave: Indústria, Mercado de Trabalho, CRAJUBAR.

\section{THE INDUSTRIAL SECTOR AND THEIR EFFECTS IN FORMAL LABOR MARKET: AN ANALYSIS FOR THE CRAJUBAR-CE TRIANGLE (2008-2018)}

\begin{abstract}
This paper aims to analyze the formal labor market from the perspective of the industrial sector in CRAJUBAR for the years 2008 and 2018, showing the panorama of the region's economy via industry, as well as the repercussions on the institutionalization of MR Cariri, in 2009. The methodology used is exploratory. The technical means used was the statistical one. The research area is the CRAJUBAR triangle, formed by the municipalities Crato, Juazeiro do Norte and Barbalha, with the formal industrial sector as the focus of analysis. Microdata is used for the years 2008 and 2018 from the RAIS/MTE and IBGE database. It's concluded that the profile of labor in the industrial sector has a better educational level, but in jobs that do not match their school reality, with low participation of women, who still face challenges in trying to equalize wages with the male class.
\end{abstract}

Keywords: Industry, Labor Market, CRAJUBAR.

Classificação JEL: E24, J01, J31. 